\title{
Creating a pediatric advisory board for engaging youth in pediatric health research: A case study
}

www.cambridge.org/cts

\section{Implementation, Policy and Community Engagement Brief Report}

Cite this article: Orellana $M$, Valdez-Soto $M$, Brockman TA, Balls-Berry JE, Zavala Rocha MG, Allyse MA, DSouza KN, Riggan KA, Juhn Y, and Patten $\mathrm{C}$. Creating a pediatric advisory board for engaging youth in pediatric health research: A case study. Journal of Clinical and

Translational Science 5: e113, 1-4. doi: 10.1017/ cts.2021.399

Received: 9 February 2021

Accepted: 17 March 2021

\section{Keywords:}

Community-engaged research; youth; pediatric advisory board; human subjects research; community

\section{Address for correspondence:}

M. Orellana, MS, Mayo Clinic Graduate School of Biomedical Science, 200 First Street SW,

Rochester, MN 55905, USA.

Email: orellana.minerva@mayo.edu

${ }^{\star}$ Co-first authors

\#Dr. Balls-Berry is now with the Department of Neurology, Washington University School of Medicine, St. Louis, MO, USA. Ms. Zavala Rocha is now with the Department of Elementary Education, Winona State University, Rochester, MN, USA

(c) The Author(s), 2021. Published by Cambridge University Press on behalf of The Association for Clinical and Translational Science. This is an Open Access article, distributed under the terms of the Creative Commons Attribution licence (http://creativecommons.org/licenses/ by/4.0/), which permits unrestricted re-use, distribution, and reproduction in any medium, provided the original work is properly cited.
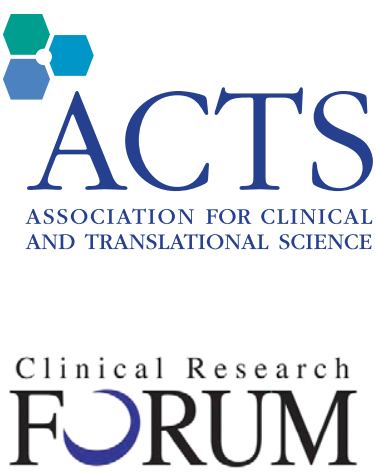

Analysis. Advocacy. Action.
Minerva Orellana ${ }^{1 *}\left(\mathbb{D}\right.$, Miguel Valdez-Soto ${ }^{2, \star}$ (1), Tabetha A. Brockman² (1), Joyce E. Balls-Berry, ${ }^{2, \#}$ (1), Maria Guadalupe Zavala Rocha\#, Megan A. Allyse ${ }^{3,4}$ (D),

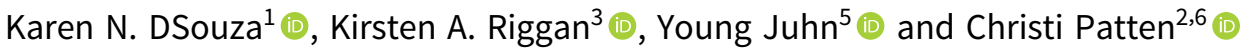

${ }^{1}$ Mayo Clinic Graduate School of Biomedical Science, Rochester, MN, USA; ${ }^{2}$ Center for Clinical and Translational Science, Community Engagement Program, Mayo Clinic, Rochester, MN, USA; ${ }^{3}$ Biomedical Ethics Research Program, Mayo Clinic, Rochester, MN, USA; ${ }^{4}$ Department of Obstetrics \& Gynecology, Mayo Clinic, Rochester, MN, USA; ${ }^{5}$ Division of Community Pediatric and Adolescent Medicine, Department of Pediatric and Adolescent Medicine, Mayo Clinic, Rochester, MN, USA and ${ }^{6}$ Department of Psychiatry and Psychology, Mayo Clinic, Rochester, MN, USA

\begin{abstract}
Youth are an understudied population requiring additional safeguards when participating in research. Their input is necessary to facilitate participation and interest in studies. To address this, Mayo Clinic established one of the first pediatric advisory boards (PAB) comprised of 18 diverse youth aged 11-17. The PAB members participated in quarterly meetings (in person and then by video conference with the advent of COVID-19) where they provided feedback to researchers on recruitment strategies, study materials, and procedures. The PAB meetings fostered bidirectional conversations with researchers on several health research topics, including mental health. Youth advisory boards can promote engagement in pediatric research.
\end{abstract}

\section{Introduction}

Youth are considered as a vulnerable population that requires additional protections to participate in human subjects research studies, such as providing assent and parent/guardian's consent [1]. Many studies document recruitment strategies on how to engage youth in research studies in the study planning process [2-4]. However, many pediatric studies have low enrollment in clinical trials [5]. Greater youth participation in research study design, implementation, and interpretation might improve the quality and success of pediatric research by increasing engagement with the research team, providing age-appropriate study materials, and assessing comprehension of participation and risk/benefits [6]. In response, our NIH-funded Center for Clinical and Translational Science (CCaTS) developed one of the first pediatric research advisory boards $(\mathrm{PAB})$ to overcome the knowledge gap in how to engage youth as meaningful partners in pediatric research.

A community-engaged research framework facilitates collaborative partnerships between academic researchers, community members, and patients who have shared interests or are connected geographically and have the same overall goal of increasing wellness [7]. A common platform for community engagement is the use of community advisory boards (CAB). CABs are typically comprised of adult patients and/or community members who advise investigators on research projects, including review of study materials and feedback on special considerations or risks/benefits to participants. CABs foster bidirectional conversations between investigators and community members [8]. Existing Mayo Clinic CABs have demonstrated success in addressing the health needs of the communities across the enterprise (Arizona, Florida, and Minnesota) [9]. However, to our knowledge, the creation of CABs that feature adolescent voices for pediatric research has not been reported in Clinical and Translational Science.

Our PAB was created with four primary goals: (1) designing pediatric research that represents the major health concerns of youth, (2) respecting the ability of youth to assent for research, (3) providing health benefits for youth through research, and (4) providing feedback to Mayo Clinic investigators on pediatric studies. This report describes the process of establishing the PAB at Mayo Clinic.

\section{Methods}

Setting

Rochester, MN USA. 


\section{PAB Member Recruitment}

Based on our experience with adult CABs, we aimed for 20 youth to join the $\mathrm{PAB}$. The $\mathrm{PAB}$ coordinator was in charge of recruiting youth as members, with the goal of achieving a wellbalanced diversity of age, gender, and ethnicity. Potential youth members were identified through existing relationships and referrals, as well as recommendations from established community partners with the Community Engagement Program team, including our adult $\mathrm{CAB}$. Locations of recruitment included African-American churches, a youth-sponsored bike club, and a homeschooling network. Given the comparatively large immigrant population in our catchment area, we also engaged community liaisons to help communicate with parents/guardians of these potential PAB members. The project was explained in ongoing conversations with the youth and their parents/ guardians. The PAB coordinator reached out to youth recommended by other stakeholders to gauge their interest before official invitations were distributed.

Interested adolescents were given personalized invitations to be part of the Mayo Clinic PAB. Once a parent/guardian's consent was obtained, invitations were either mailed or hand-delivered in December 2018. Youth provided assent to participate in the $\mathrm{PAB}$. Parents/guardians were asked to submit authorization for use of the youth's image and video and co-sign a W-9 form for remuneration. The PAB members were paid $\$ 25$ for each session they attended and a meal was provided.

\section{Training}

Prior to giving feedback to researchers, PAB members were trained in the research process, human subject research, research ethics, and vulnerable populations. The first meeting in April 2019 was an introduction to the PAB members and staff. It also involved a presentation about the research process and special populations. The second meeting held in May 2019 focused on human research training and a speed information session with scientists. The July 2019 meeting involved learning about research ethics, vulnerable populations, and a researcher presentation. After human subjects research training in the initial sessions, the researchers presented their material of interest on July 2019, October 2019, and January 2020.

\section{Meeting Structure}

In contrast to the traditional $\mathrm{CAB}$ structure, the team decided that the $\mathrm{PAB}$ would not have a Chair because of uncertainty that youth would be comfortable volunteering for this role. Instead, the PAB coordinator facilitated the meetings. Subsequently, there has been discussion of instituting a youth co-Chair for members who feel more confident or comfortable.

The PAB was established with quarterly meetings with the potential for expanding the frequency of meetings depending on the need of PAB members and researchers. Parents were not present at PAB meetings. All of the PAB meetings had a set agenda. The meetings were initiated with welcome and roundtable updates by the $\mathrm{PAB}$ coordinator with the $\mathrm{PAB}$ members. The speaker was then introduced, proceeded with their research presentation, and had an open discussion with the PAB members. The speakers were invited to come earlier to socialize with the PAB members if they were interested. Detailed minutes were taken at each meeting.
Table 1. Demographics of pediatric advisory board

\begin{tabular}{lcc}
\hline & Mean & SD \\
\hline Age (years) & 14.1 & 1.7 \\
\hline & $\mathbf{n}$ & $\%$ \\
\hline Race/Ethnicity & & \\
\hline Black/African Ancestry/African-American & 3 & $20 \%$ \\
\hline White/Caucasian & 4 & $27 \%$ \\
\hline Hispanic/Latinx & 3 & $20 \%$ \\
\hline More than one (+2) & 5 & $33 \%$ \\
\hline Education Level & & \\
\hline Elementary & 2 & $13 \%$ \\
\hline Middle school & 3 & $20 \%$ \\
\hline High school & 10 & $67 \%$ \\
\hline
\end{tabular}

\section{Researcher Presentations}

The availability of the $\mathrm{PAB}$ to researchers was promoted by the coordinator and other Community Engagement Program staff through word-of-mouth referrals and consultations. Subsequently, the $\mathrm{PAB}$ has been advertised through Mayo Clinic organizational websites, newsletters, and presentations.

The PAB coordinator first met with the researchers to see if their research and needs met the scope of the PAB. An invitation to speak at one of the $\mathrm{PAB}$ sessions was then extended. A presenter form was emailed to the researcher asking them to limit their presentation to five slides and three questions, given the age demographic of the $\mathrm{PAB}$. If the $\mathrm{PAB}$ coordinator felt the questions were too difficult or would not be readily understood by the $\mathrm{PAB}$ members, the researcher was asked to reword and resubmit for review.

\section{Results}

\section{Demographics}

A total of 19 invitations to be part of the PAB were sent. All were accepted except one due to a work conflict. Our recruitment goal was reached with 9 girls and 9 boys aged 11-17 joining the PAB All lived in Olmsted County or surrounding communities. Demographic information was missing for three members including one who moved out of the catchment area (Table 1). Quarterly $\mathrm{PAB}$ attendance ranged from 13 to 18 members with the exception of the January 2020 session which had 5 members.

\section{Feedback}

The topics of each of the first five meetings of the PAB are presented in Table 2 . Two of the three investigators were initially presented to the $\mathrm{PAB}$ specialized in pediatrics and the other in adolescent psychology. The PAB provided feedback to speakers such as comments to help increase awareness of research studies for adolescents. Some examples included how to direct research flyers or letters to the adolescent's interest and not their parents. PAB members provided suggestions of locations to advertise research studies and to conduct focus groups. Many of the sessions were bidirectional with members advocating for health concerns in their age group, including mental health and vaping. Other examples are listed in Table 2. 
Table 2. Meeting purpose and topic(s)

\begin{tabular}{|c|c|c|c|}
\hline Date & Purpose & Topic(s) & Questions to the Pediatric Advisory Board (PAB) \\
\hline April 2019 & Welcome/Introduction & $\begin{array}{l}\text { - Introductory meeting for members to } \\
\text { meet each other and the scientific team }\end{array}$ & Training sessions \\
\hline May 2019 & Human Subject Training & $\begin{array}{l}\text { - Training provided to PAB members on } \\
\text { responsible conduct of research }\end{array}$ & Training sessions \\
\hline \multirow[t]{2}{*}{ July 2019} & $\begin{array}{l}\text { Learning about Vulnerable } \\
\text { Populations and Research Ethics }\end{array}$ & $\begin{array}{l}\text { - Active discussion on traditionally vulner- } \\
\text { able populations that have experienced } \\
\text { historical mistrust related to health } \\
\text { research }\end{array}$ & Training sessions \\
\hline & Depression in Adolescents & $\begin{array}{l}\text { - Examples of creating awareness of the } \\
\text { study in adolescents }\end{array}$ & $\begin{array}{l}\text { What is the best way to create awareness of } \\
\text { the study with teenagers? }\end{array}$ \\
\hline October 2019 & $\begin{array}{l}\text { Experiences of Interpersonal } \\
\text { Discrimination in Pediatric } \\
\text { Settings }\end{array}$ & $\begin{array}{l}\text { - How to advertise the study letter to } \\
\text { parents and adolescents } \\
\text { - Where to hold the focus groups } \\
\text { - Thoughts on safe and/or support space }\end{array}$ & $\begin{array}{l}\text { What do you think about this letter that will } \\
\text { be mailed to parents and adolescents? } \\
\text { - Any other guidelines do you all suggest we } \\
\text { follow to keep this focus group a safe and } \\
\text { supportive space? }\end{array}$ \\
\hline \multirow[t]{2}{*}{ January 2020} & $\begin{array}{l}\text { Thoughts on PAB Members } \\
\text { Being in a Research Study }\end{array}$ & $\begin{array}{l}\text { - Thoughts on providing advice } \\
\text { - How interviews should be done } \\
\text { - Who would benefit from the study }\end{array}$ & $\begin{array}{l}\text { - How you feel about providing advice to } \\
\text { researchers? }\end{array}$ \\
\hline & $\begin{array}{l}\text { Study on Attitudes, Beliefs, } \\
\text { Behaviors, and Clinical Practices } \\
\text { Related to Youth Marijuana and } \\
\text { Cannabidiol use }\end{array}$ & $\begin{array}{l}\text { - A series of questions pertaining to the } \\
\text { comfort levels of someone they know at } \\
\text { a doctor's office with their parent discus- } \\
\text { sing marijuana use }\end{array}$ & $\begin{array}{l}\text { - How do you think a parent would feel about } \\
\text { marijuana use? } \\
\text { What is it about the parent being there would } \\
\text { take away from that open communication } \\
\text { between the child and doctor? }\end{array}$ \\
\hline
\end{tabular}

\section{Discussion}

Children and adolescents are defined as a vulnerable research population who require special considerations. However, our case study indicates that researchers can seek out youth for their input to better improve the recruitment and retention of children and adolescents in their studies.

Other study-specific youth advisory boards focused on limited health topics or improving organizations [10-13]. Some youth advisory boards are comprised of adult members discussing topics pertaining to youths [14]. A few advisory boards are based in hospitals to help improve pediatric treatments including at Children's Minnesota, Boston Children's Hospital, and Children's Mercy in Kansas City [15-17]. To our knowledge, the Mayo Clinic $\mathrm{PAB}$ in Rochester, Minnesota is one of the first of its kind. This is the first mention of a $\mathrm{PAB}$ created for bidirectional engagement, as well as advising on research studies focusing on youth participants in Clinical and Translational Science.

The PAB was created to be diverse and reflect the demographics of the US population and not only of Rochester, Minnesota. It is intended for researchers to seek out feedback for improving recruitment or reviewing study material for studies focused on adolescents. Researchers left the meetings with suggestions that would be implemented in their studies.

The PAB has been featured in both youth and adult-focused public media outlets for its role in creating opportunities for youth to have a voice in health-related research [18-20]. Additionally, the $\mathrm{PAB}$ provided adolescents a voice on studies featuring people like them and for discussion of health disparities prevalent in their own communities. Other institutions interested in conducting community-engaged research, particularly pediatric research, may also benefit from engagement with PAB.

\section{Limitations}

Given the lack of precedence for the PAB model, there were initial challenges, including education of the PAB members to establish a base of knowledge from which to provide feedback. To understand members' experience, a study was conducted to assess initial challenges and build upon the successes of the PAB. Despite achieving gender and racial/ethnic diversity of members, there is a need for more Asian representation on the board. We aim to include youth who do not identify within traditional gender roles. In time, we hope to address this as future spots are made available on the PAB.

\section{Future Directions}

The $\mathrm{PAB}$ continues to meet quarterly and has transitioned to a video conferencing format following COVID-19 guidelines. Currently, there is a waiting list for membership. Future directions include transitioning of graduating $\mathrm{PAB}$ members into the Mayo Clinic $\mathrm{CAB}$ or future inclusion as an observer. Feedback can include helping researchers adapt to continue researching during these unprecedented times. $\mathrm{PAB}$ members could take more active roles in the entire research process such as initiating their own research projects on their topics of interest.

Acknowledgments. We would like to acknowledge the members of the Mayo Clinic Pediatric Advisory Board. We would like to thank Laura Meiners for PAB operational support. This publication was supported by Grant Number UL1 TR002377 from the National Center for Advancing Translational Sciences (NCATS). Its contents are solely the responsibility of the authors and do not necessarily represent the official views of the NIH.

Disclosures. The authors have no conflicts of interest to declare.

Ethical Statement. The creation of the PAB did not require IRB protocol but we received parent/guardian's consent and youth's consent.

\section{References}

1. Office for Human Research Protections. Special Protections for Children as Research Subjects. 2016. 
2. Hawke LD, Relihan J, Miller J, et al. Engaging youth in research planning, design and execution: Practical recommendations for researchers. Health Expectations 2018; 21: 944-949. doi: 10.1111/hex.12795.

3. Powers JL, Tiffany JS. Engaging youth in participatory research and evaluation. Journal of Public Health Management and Practice 2006; 12: S79-S87.

4. Checkoway B, Richards-Schuster K. Youth participation in community evaluation research. American Journal of Evaluation, 2003; 24: 21-33.

5. Bourgeois FT, Hwang TJ. The pediatric research equity act moves into adolescence. JAMA, 2017; 317: 259-260. doi: 10.1001/jama.2016.18131.

6. Paquette ET, Palac H, Bair E, et al. The importance of engaging children in research decision-making: a preliminary mixed-methods study. Ethics \& Human Research 2020; 42: 12-20.

7. CDC. Principles of Community Engagement, Second Edition. Washington, DC: NIH Publication, 2011.

8. Matthews AK, Anderson EE, Willis M, Castillo A, Choure W. A community engagement advisory board as a strategy to improve research engagement and build institutional capacity for community-engaged research. Journal of Clinical and Translational Science, 2018; 2: 66-72. doi: 10. 1017/cts.2018.14.

9. Patten CA, Albertie ML, Chamie CA, et al. Addressing community health needs through community engagement research advisory boards. Journal of Clinical and Translational Science 2019; 3: 125-128. doi: 10.1017/cts. 2019.366.

10. Children's Mental Health Project and Environmental or Behavioral Disorders Project. Youth Advisory Board [Internet], 2020 [cited Jan 15, 2021]. (https://www.pacer.org/cmh/youth-advisory-board/about.asp)

11. School-Based Health Alliance. Bringing Student Engagement to the Forefront of School-Based Health Care. Youth Advisory Council 2020 [Internet], 2020 [cited Jan 15, 2021]. (http://www.sbh4all.org/youthadvisory-council/)
12. my Health For Teens \& Young Adults. Youth Advisory Board [Internet], 2020 [cited Jan 15, 2021]. (https://myhealthmn.org/youthadvisory-board/)

13. American Psychological Association. APA Children, Youth and Families Office Youth Advisory Board [Internet], 2019 [cited Jan 15, 2021]. (https:// www.apa.org/pi/families/youth-advisory-board)

14. youth tech health. Youth Advisory Board [Internet], 2020 [cited Jan 15, 2021]. (https://yth.org/about/youth-advisory-board/)

15. Children's Minnesota. Youth Advisory Council. Patient \& Family Councils [Internet], 2020 [cited Jan 15, 2021]. (https://www. childrensmn.org/support-childrens/volunteer/patient-family-councils/ youth-advisory-council/)

16. Boston's Children Hospital. Advisory Boards [Internet], 2020 [cited Jan 15, 2021]. (https://www.childrenshospital.org/research/centers-departmentalprograms/center-of-excellence-for-pediatric-quality-measurement-cepqm/ cepqm-leadership/advisory-boards)

17. Children's Mercy Kansas City. Teen Advisory Board [Internet], 2020 [cited Jan 15, 2021]. (https://www.childrensmercy.org/about-us/advisoryboards/teen-advisory-board/)

18. Inside Mayo Clinic Research. Kids are Bringing a Critical Point of View to Research [Internet], 2019 [cited Jan 15, 2021]

19. In the Loop. Pediatric advisory board gives kids a voice in research that affects them. In the Loop [Internet], November 12, 2019 [cited Jan 15, 2021]. (https://intheloop.mayoclinic.org/2019/11/12/pediatric-advisoryboard-gives-kids-a-voice-in-research-that-affects-them/?_ga $=2.256156674$. 800189847.1621448240-2080233718.1621448240)

20. Science News for Students. A first: kids advise hospital researchers on their medical studies, in Science \& Society [Internet], 2020 [cited Jan 15, 2021] (https://www.sciencenewsforstudents.org/article/kids-advise-hospitalresearchers-on-their-medical-studies) 